\title{
Evolution of volatile compounds in gluten-free bread: from dough to crumb
}

$\underline{\text { Joana Pico }}^{\mathrm{a}^{*}}$, Mario M. Martínez ${ }^{\text {b,c }}$, José Bernal ${ }^{\text {a }}$, Manuel Gómez ${ }^{\mathrm{c}}$

${ }^{a}$ I.U.Cinquima, Analytical Chemistry Group, University of Valladolid, Paseo de Belén Street 7, E-47011 Valladolid, Spain.

b Present address: Whistler Center for Carbohydrate Research, Department of Food Science, Purdue University, 745 Agricultural Mall Drive, West Lafayatte, IN 47906, USA.

${ }^{\mathrm{c}}$ Food Technology Area, E.T.S. Ingenierías Agrarias, University of Valladolid, Madrid Avenue 57, E- 34071 Palencia, Spain.

*Corresponding author: Joana Pico . e-mail: joana.pico@uva.es

\section{Highlights}

$\checkmark 31$ common volatile compounds reported in breads were found in maize starch bread.

$\checkmark$ Fermentation alcohols, diacetyl, acetoin and acetic acid were abundant in dough.

$\checkmark$ Besides dough volatiles, hexanal, 1-octen-3-ol and nonenal increased in crumb.

$\checkmark$ One-way Anova results indicated 7 behaviours of volatiles from dough to crumb. 


\begin{abstract}
Understanding the evolution of volatile compounds from dough to crumb is necessary in order to improve the weak aroma of gluten-free breads. Additionally, sensitive analytical methods are required to detect small changes. In the present study, a solvent extraction method combined with GC/MS was selected to examine the evolution of 31 principal volatile compounds from the beginning of fermentation to the end of baking in maize starch bread. During fermentation, only hexanal, hexanoic acid, benzaldehyde, benzyl alcohol, furfural and furfuryl alcohol remained constant whereas the rest became more abundant. After baking, 2,3-butanedione, 1-propanol, 2-methyl-1-propanol, 3/2methyl-1-butanol and ethyl octanoate were evaporated whereas the other volatile compounds increased. The alcohols from fermentation, 2,3-butanedione, acetoin, acetic acid, isobutyric acid and ethyl octanoate, were the main volatile compounds in dough; all of them were formed during fermentation. In crumb, alongside those compounds, hexanal, 1-octen-3-ol and nonanal, produced from lipid oxidation, were also important contributors.
\end{abstract}

Key words: gluten-free bread crumb; gluten-free dough; maize starch; volatile compounds; solvent extraction; GC/MS.

Abbreviations: ANOVA (analysis of variance); FD (flavour dilution factor); GC/MS (gas chromatography/mass spectrometry); HPMC (hydroxylpropyl methylcellulose); OAV (odour activity value); OT (odour threshold); PCA (principal component analysis); PC1 (first principal component); SIM (selected ion monitoring) 


\section{Introduction}

The aroma of bread is one of the main characteristics that influence the customers' choice. There can be no doubt that the ingredients of the recipe should affect the final aroma of bread. In fact, when the bread is elaborated with gluten-free flours, the resulting aroma is weaker than those elaborated with wheat or rye (Pacyński, Wojtasiak, \& Mildner-Szkudlarz, 2015). The processes that lead to the final aroma of bread, such as fermentation, lipid oxidation or Maillard reactions, strongly depend not only on the recipe but also on the fermentation and baking conditions (Cho \& Peterson, 2010). Thus, it is really important to determine the evolution of the volatile compounds from the 0 min fermented dough to the fermented dough and finally to the baked bread in order to understand their generation in the different steps. Therefore, the processing of the gluten-free breads could be modified to achieve a stronger, improved aroma. However there are only a few studies regarding the aroma of gluten-free breads. Furthermore, they analyse the crumb and crust together without specifying where the volatile compounds come from (Aguilar, Albanell, Miñarro, Gallardo, \& Capellas, 2015; Poinot et al., 2009). To our knowledge, there is no research regarding the aroma of gluten-free doughs and its evolution to the crumb. Only one research study regarding the evolution of volatile compounds was found, but in wheat bread (Makhoul et al., 2015).

The selected analytical technique is also important because trace analyses are necessary to detect small differences between the different steps of bread production and, above all, between the different stages of fermentation. Solvent extraction methodologies possess in general lower limits of detection than methodologies using head space (Pico,

Gómez, Bernal, \& Bernal, 2016) and allow the detection of a higher number of compounds (Majcher \& Jeleń, 2009). The most employed extractant is dichloromethane 
(Gassenmeier \& Schieberle, 1995; Schieberle \& Grosch, 1994; Zehentbauer \& Grosch, 1998) and only for a few compounds, normally acidic compounds, diethyl ether is also reported (Zehentbauer \& Grosch, 1998). Moreover, solvent extraction methodologies have been shown to result in extracts rich in high-molecular weight volatile compounds whereas solid-phase microextraction (SPME) to result in extracts rich in low-molecular weight volatile compounds (Mayuoni-kirshinbaum, Tietel, Porat, \& Ulrich, 2012). Thus, SPME is may be beneficial for volatile compounds that are very volatile and coelute with the solvent. On the other hand, solvent extraction treatments are more tedious and need the use of organic solvents (Pico et al., 2016). Therefore, solvent extraction methodologies and headspace methodologies have been frequently employed in a complementary way (Corral, Salvador \& Flores, 2015; Klensporf \& Jeleń, 2008; Majcher \& Jeleń, 2009). With the purpose of detecting small changes in the concentration of the most important compounds, a solvent extraction method for volatile compounds in bread with low limits of detection was selected.

Therefore, the goal of this study was to understand and explain the evolution of the most common volatile compounds in gluten-free breads from the fermented dough after 0 min, 45 min and 90 min to the baked crumb employing a sensitive solvent extraction GC/MS methodology. In this way it would be possible to tentatively establish conclusions about ways to improve the aroma of gluten-free breads.

\section{Materials and methods}

\subsection{Materials}

Maize starch (Miwon Daesang, Seul, Korea), hydroxylpropyl methylcellulose (HPMC)

(Methocel ${ }^{\mathrm{TM}}$ K4M, Dow Chemicals, Michigan, USA) and Saccharomyces cerevisiae 
(Saf-instant yeast) (Lesaffre, Lille, France) were used. Sucrose, salt and sunflower oil were purchased from the local market and tap water was employed.

To check the retention time and the mass spectra of the main volatile compounds, the 31 analytical standards listed in Table 1 were purchased from Sigma Aldrich (Gillingham, UK). The purity of all the standards was higher than $98 \%$ and, in many cases, completely pure.

\subsection{Methods}

\subsubsection{Gluten-free bread making}

The following ingredients, as a \% on starch basis, were employed: sunflower oil (3\%), sucrose (5\%), salt (1.8\%), instant yeast (3\%), HPMC (2\%) and water (100\%). The dough was elaborated with a basis of $700 \mathrm{~g}( \pm 0.05 \mathrm{~g})$ of starch and the amount of starch and water was adjusted to an average moisture content of $12 \%$. The ingredients were mixed using a Kitchen-Aid Professional mixer (KPM5, KitchenAid, St. Joseph, Michigan, USA) for $8 \mathrm{~min}$ at speed $56 \mathrm{rpm}$.

Four aluminum tins were filled with $100 \mathrm{~g}( \pm 0.05 \mathrm{~g})$ of kneaded dough. $5 \mathrm{~mL}$ of a mixture of methyl octanoate and methyl decanoate (20 $\mathrm{g} \mathrm{L}^{-1}$, dimethyl sulfide) were added to one of them ( 0 min fermented dough) in order to inhibit the fermentation evolution (data not shown) and finally it was frozen at $-20^{\circ} \mathrm{C}$. The other two were left for fermentation for $45 \mathrm{~min}$ and $90 \mathrm{~min}$ in a chamber at $30{ }^{\circ} \mathrm{C}$ with $90 \%$ of humidity and then their fermentation inhibition was performed as explained (45 min fermented dough and 90 min fermented dough). The frozen doughs were left at room temperature 30 min before their aroma analyses. The last one was left to fermentation for $90 \mathrm{~min}$ and finally it was baked at $190{ }^{\circ} \mathrm{C}$ for $40 \mathrm{~min}$. After baking, the gluten-free bread was left at room temperature for $30 \mathrm{~min}$ and cut into loaves of $5 \mathrm{~cm}$ long. The crumb was separated from $1 \mathrm{~cm}$ to crust, to avoid the crumb contamination with crust volatile compounds. 
Finally, the crumb was grounded and frozen at $-20{ }^{\circ} \mathrm{C}$. The frozen crumb was left to room temperature $30 \mathrm{~min}$ before its aroma analysis. Each dough and crumb was prepared in duplicate $(\mathrm{n}=2)$.

\subsubsection{Volatile compounds analyses: Solvent extraction \& GC/MS}

The 0 min, 45 min and 90 min fermented doughs as well as the crumb were analysed following the lipases extraction method (Pico, Nozal, Gómez and Bernal, 2016): $50 \mathrm{~g}$ of each sample were grounded with liquid nitrogen and then submitted to a Soxhlet extraction for $5 \mathrm{~h}$ at $40{ }^{\circ} \mathrm{C}$ with a mixture of diethyl ether/dichloromethane, which contained $25 \mu \mathrm{L}$ lipase enzyme (Lipozyme CALB $\mathrm{L}^{\circ}$ ) in order to hydrolyse the fat. After that, the extract was concentrated by means of a Vigreux column and injected onto the GC/MS. It is a suitable method to examine the evolution of volatile compounds from dough to crumb since the reported limits of detection were lower than $35 \mu \mathrm{g} \mathrm{Kg}^{-1}$. Analyses were performed in duplicate $(n=2)$.

GC-MS analyses were performed on a 7890A gas chromatograph coupled to a 5975C single quadrupole mass spectrometer detector equipped with a 7683B automatic injector and Chemstation 5975C software, all from Agilent Technologies (Santa Clara, California, USA). Separation was achieved on a polar ZB-Wax column (100\% polyethylene glycol, $60 \mathrm{~m} \times 0.25 \mathrm{~mm} \mathrm{ID} \times 0.25 \mu \mathrm{m}$ ) obtained from Zebron (Phenomenex, New South Wales, Australia). The gas chromatograph was operated under programmed temperature conditions, ranging from $45^{\circ} \mathrm{C}(1.5 \mathrm{~min})$ to $100{ }^{\circ} \mathrm{C}(0 \mathrm{~min})$ at $7{ }^{\circ} \mathrm{C} / \mathrm{min}$, after which the temperature was increased to $114{ }^{\circ} \mathrm{C}(3 \mathrm{~min})$ at $6{ }^{\circ} \mathrm{C} / \mathrm{min}$, and then to $136{ }^{\circ} \mathrm{C}(0 \mathrm{~min})$ at $1.5{ }^{\circ} \mathrm{C} / \mathrm{min}$. Finally, the temperature was raised to $245{ }^{\circ} \mathrm{C}$ at $85{ }^{\circ} \mathrm{C}$ /min. It was held for 25 min in order to elute the hydrolysed fat (glicerol and free fatty acids). The carrier gas was also helium, at a flow rate of $1.1 \mathrm{~mL} / \mathrm{min}$. The interface, ion source and quadrupole temperatures were $250^{\circ} \mathrm{C}, 230{ }^{\circ} \mathrm{C}$ and $150^{\circ} \mathrm{C}$, respectively. 
Analyses were performed in SIM mode, operating in positive electron impact mode with ionization energy of $70 \mathrm{eV}$. All the volatile compounds were identified and confirmed by comparison of their retention times and mass spectra (target and qualifier ions) with standards (Table 1) and with the Mass Spectra Library (Wiley 7N edition). Firstly, the standard corresponding to each volatile compound was injected individually in order to unequivocally determine its retention time. After that, the mixture of the 31 standards was injected to check the final retention time. This mixture of standards was injected simultaneously with each sample. The retention time of most of them was slightly different from dough to crumb (1 - $1.5 \mathrm{~min}$ of delay in dough) due to the different matrix and the presence of inhibitor substances in the dough.

\subsubsection{Data analysis.}

In order to better represent and interpret the results of the evolution of each volatile compound in the different samples ( 0 min, 45 min and 90 min fermented doughs and the crumb), a one-way analysis of variance of the peak areas was calculated. The Oneway Anova was computed by the software Statgraphics Centurion version XVII (Statpoint Technologies, Warrenton, Virginia). The total number of replicates was four $(n=4)$, with the dough and crumb prepared in duplicate and, in turn, analysed in duplicate. Principal component analysis (PCA) of the three doughs was calculated with the software Latentix (version 2.00, Latent5), with all GC/MS data autoscaled prior to the analysis.

\section{Results and discussion}

\subsection{Evolution of the main volatile compounds during fermentation.}

A total of 31 volatile compounds were found and examined to understand their generation and evolution from dough to crumb in maize starch bread, integrating the 
peak area of each volatile compound. These 31 volatile compounds have been commonly reported in wheat bread dough (Martínez-Anaya, 1996) and crumb (Birch, Petersen, \& Hansen, 2014; Pico, Bernal, \& Gómez, 2015). Volatile compounds like, 3/2-methyl-1-butanol, benzyl alcohol, phenylethyl alcohol, phenylacetaldehyde, 2,3butanedione, acetoin or 3-methylbutanoic acid, have been reported to have a positive impact in the final aroma of wheat bread, whereas 1-octen-3-ol, 2,4-(E,E)-decadienal, benzaldehyde, hexanal or methional, have been associated with a negative impact. 2(E)-nonanal, 3-methyl-1-butanol, hexanal, 2,3-butanedione and phenylacetaldehyde have been reported having the highest odour activity values (OAVs). Meanwhile, nonanal and 1-octen-3-ol were important in wheat bread crumb with OAVs higher than 4, and 2-phenylethanol, ethyl octanoate, 2,4-(E,E)-decadienal, acetic acid, methional and 4-vynilguaiacol with flavour dilution (FD) factors higher than 64. Therefore, we hypothesized that these compounds could also appear in the maize starch of breads. Among the selected volatile compounds, some come from fermentation (including Ehrlich pathway and glycolisis), lipid oxidation, Maillard (including Strecker compounds) or other origins, as shown in Table 1.

During kneading there is an increase in the enzymatic reactions that result in substrates useful for the generation of volatile compounds (Guinet \& Godon, 1994). Maize starch is formed mainly by $70-80 \%$ of amylopectin and $20-30 \%$ of amylose, which can be broken down by the combined action of amylases (Robyt, 2009), leading finally, among others, to maltose units. Yeast species common in breadmaking have saturated kinetics for maltose and also possess $\alpha$-glucosidases that hydrolyse the maltose into glucose units. Glucose is fast consumed by the yeast while maltose accumulates at first and only starts to be used when the levels of monosaccharides are low (Martínez-Anaya, 1996). The sugar added to the dough is also responsible for the fermentable substrate, which 
could be partially metabolised by the yeast into glucose and fructose (Martínez-Anaya, 1996), leading to small amounts of volatile compounds during kneading. The amount of proteases and lipases in starch and the rest of the ingredients could be considered negligible, thus the generation of amino acids and free fatty acids due to hydrolysis during kneading could be neglected. Therefore, mainly small amounts of volatile compounds from fermentation were expected in the 0 min fermented dough. On the other hand, the addition of oil to the recipe implied the possible presence of small amounts of volatile compounds from lipid oxidation (Guillén, Cabo, Ibargoitia, \& Ruiz, 2005; Poinot et al., 2009) as well as the incorporation of lipoxygenases (Márczy, Németh, Samu, Háger-veress et Szajáni, 2002). These lipoxygenases could be able to participate in lipid oxidation processes, generating hydroperoxides during fermentation that are broken during baking, increasing the number of volatile compounds. Moreover, the mixing conditions influenced oxygen incorporation from the air, increasing the nonenzymatic lipid oxidations (Gardner, 1975) as well as the contact between lipoxygenase and the substrate, resulting in greater amounts of hydroperoxides and in the oxidation of carotenoid pigments (Martínez-Anaya, 1996) of the sunflower oil.

All of this is in concordance with the volatile profile analysed in the 0 min fermented dough (Table 2), which was characterised by volatile compounds from fermentation such as 2,3-butanedione, 2-methyl-1-propanol, 3-methyl-1-butanol, 2-methyl-1-butanol, acetic acid, 2,3-butanediol, isobutyric acid and ethyl octanoate. These volatile compounds should have been generated in a mild fermentation given during kneading and in the brief time needed to inhibit the fermentation with the mixture solution of methyl octanoate and methyl decanoate. All of them have been reported as main volatile compounds in wheat bread dough (Martínez-Anaya, 1996). Small amounts of hexanal, 
1-hexanol, 1-octen-3-ol, nonanal and 2,4-decadienal were also found, although only hexanal is expected in wheat dough (Martínez-Anaya, 1996).

When the fermentation time increased to $45 \mathrm{~min}$, apart from the fermentation volatile compounds previously mentioned in the 0 min fermented dough, 1-propanol, acetoin and phenylethyl alcohol appeared to be main volatile compounds, also reported as important aroma compounds in wheat dough (Martínez-Anaya, 1996). These eleven main volatile compounds from fermentation also arose in the 90 min fermented dough, as expected, except ethyl octanoate. A PCA of the peak areas of the doughs was calculated in order to clarify, as a general tendency, in which stage of the fermentation the volatile compounds are more intensively generated (Figure 1). It was observed that the PC1 explained almost $80 \%$ of the variance of the original variables, which grouped all the volatile compounds in the positive component of the PC1 and only ethyl octanoate in the negative one. Ethyl octanoate was the only volatile compound that decreased during fermentation while the rest increased when comparing the $0 \mathrm{~min}$ fermented dough with the 90 min fermented. As 90 min fermented dough (positive PC1 of scores plot, Figure 1a) contained the highest amounts of all volatile compounds (positive PC1 of loadings plot, Figure 1b, expanded in b1, b2 and b3), they should have been generated in the last part of the fermentation since 45 min and 0 min fermented dough were located in the negative PC1 of scores plot, where only ethyl octanoate was localised. Esters in fermentation have been reported to be produced from the fatty acids metabolism in the yeast cell as a way to remove the toxic fatty acids (Nordstrom, 1964). Maize starch does not contain an important amount of fatty acids, thus ethyl octanoate may have been produced from the small portion of octanoic acid at the beginning of the fermentation. Depending on the nutrient composition of the medium, that is to say the concentration of acyl Co-A and ethanol and the activity of enzymes, the esterification 
equilibrium may be displaced to the hydrolysis reaction (Saeraens, Delvaux, Verstrepen, Van Dijck, Thevelein, \& Delvaux, 2008), giving again the acid and the alcohol, probably due to the Châtelier's principle.

\subsection{Evolution of the main volatile compounds from fermentation to baking}

The final profile of the maize starch crumb revealed compounds that have been commonly reported in wheat bread crumb (Birch, Petersen, \& Hansen, 2013), with a similar profile to wheat bread crumb when pre-ferments are employed (Gassenmeier \& Schieberle, 1995). On the other hand, all the volatile compounds analysed in the present study have been reported previously in gluten-free breads that contain maize starch in the recipe (Aguilar et al., 2015; Pacyński et al., 2015), except butanoic acid, 3methylbutanoic acid, 2-methylbutanoic acid and 2-methylpropanoic acid.

2-Pentylfuran is the only volatile compound that was exclusively generated during baking, since it was not detected in the dough. 2-Pentylfuran has been reported as the most common aroma-active furan in wheat bread crumb and floral-fruity notes (Birch et al., 2014). Although it can be generated by fermenatation, lipid oxidation and Maillard reactions (Table 1), it is mainly generated from 2-(E)-Nonenal during baking (Birch et al., 2014). The other 50 volatile compounds appeared in all the doughs and crumb, most of them being higher in crumb due in some cases to the development of Maillard reactions, in other cases to the cleavage of the hydroperoxides from the lipid oxidation and also due to the transformation of some compounds catalysed by the heat of the oven.

The results from the one-way Anova of the four samples ( 0 min, $45 \mathrm{~min}$ and $90 \mathrm{~min}$ fermented doughs and the final crumb) are shown in Table 2. Regarding the significant differences between the doughs and the crumb, 7 different behaviours of the volatile compounds were found as a pattern, as is summarised in Table 3. 


\subsubsection{Volatile compounds that increase during fermentation}

Depending on the conditions of the medium, as is reflected in Table 3, there were compounds that increased continuously during fermentation (behaviour B), compounds that increased from 0 min to 45 min of fermentation and then stayed almost constant until the fermentation ended (behaviour D and E) and there were compounds that only increased between $45 \mathrm{~min}$ and the end of the fermentation at 90 min (behaviour C).

The alcohols 1-propanol, 2-methyl-1-propanol, 3-methyl-1-butanol and 2-methyl-1butanol as well as the ester ethyl lactate increased along the entire fermentation process since they are compounds that are exclusively produced by the yeast activity (Grosch \& Schieberle, 1997; Jensen, Oestdal, Skibsted, Larsen, \& Thybo, 2011; Martínez-Anaya, 1996; Paraskevopoulou, Chrysanthou, \& Koutidou, 2012). Although acetoin, acetic acid, 2,3-butanediol and phenylethyl alcohol can be generated by fermentation or by Maillard reactions (Poinot, Arvisenet, Grua-Priol, Fillonneau, Le-Bail, \& Prost, 2010), the yeast activity prevails during fermentation, since the temperature reached in this phase is not enough to develop Maillard reactions. Therefore, these compounds also increased continuously through the fermentation process. Nonanal and 2-(E)-nonenal, which come from lipid oxidation processes (Birch et al., 2013), also increased from 0 to 90 min of fermentation. This can be attributed to non-enzymatic reactions of lipids oxidation (Gardner 1975) that could take place during fermentation.

On the other hand, 2,4-(E,E)-decadienal and 1-hexanol are also volatile compounds that come from lipid oxidation processes (Poinot et al., 2010; Quílez, Ruiz, \& Romero, 2006), but they persisted more or less constant in the first part of the fermentation and started to increase from $45 \mathrm{~min}$ to $90 \mathrm{~min}$, probably due to the non-enzymatic reactions. Likewise, all the acids isobutyric (2-methylpropanoic), 3-methylbutyric and 2methylbutyric showed the higher increase in their peak area also from 45 to 90 min of 
fermentation, which could be the result of the oxidation of the corresponding Ehrlich amino acids (Berry \& Watson, 1987), process that seemed to need more time to take place. Butyric acid showed the same pattern as the other acids, which is produced in the fatty acid synthase pathway in the yeast cell (Berry \& Watson, 1987), metabolism that also seemed to need more time to be effective. 2,3-butanedione, generated through fermentation and Maillard reactions (Poinot et al., 2010), was also more intensively produced between $45 \mathrm{~min}$ and the end of the fermentation at 90 min. 2,3-butanedione can be produced from acetoin via glycolisis (Drapon \& Richard-Molard, 1979) but can be also enzymatically degraded to 2,3-butanediol (Ehsani, Fernandez, Biosca, Julien \& Dequin, 2009). This explains why it almost stayed constant until $45 \mathrm{~min}$ of fermentation, as a consequence of the compensation of both effects. Finally, 4vinylguaiacol was surprisingly found in dough, since it is mainly generated by Maillard reactions (Pico et al., 2015) during baking. The low amount present in the 0 min and 45 min fermented dough as well as the increase up to 90 min has been reported to be attributed to the activity of feruloyl esterases produced by the yeast (Coghe, Benoot, Delvaux, Vanderhaegen \& Delvaux, 2004), activity that appeared to be more intensive in the second part of the fermentation.

Finally, there were only four volatile compounds that effectively increased at the beginning of the fermentation and stayed constant after $45 \mathrm{~min}$, probably due to the reduction or removal of some precursor, as the amino acid methionine in the case of methional (Frasse, Lambert, Richard-Molard, \& Chiron, 1993) or phenylalanine (Jensen et al., 2011) in the case of phenylacetaldehyde. 1-octen-3-ol (lipid oxidation compound) and butyrolactone (mainly derived from yeast metabolism although it can be also generated by Maillard) exhibited also this behaviour.

\subsubsection{Volatile compounds that stay constant during fermentation}


The couples hexanal-hexanoic acid, furfuryl alcohol-furfural as well as benzyl alcoholbenzaldehyde did not suffer significant changes in their peak area during fermentation (behaviour F), which could be attributed to a redox equilibrium between them. Thus, furfuryl alcohol has been reported to come from furfural's reduction by the action of Saccharomyces cerevisiae (Villa et al., 1992). For its part, hexanoic acid has been reported to derive from the oxidation of hexanal during the lipids oxidation process (Pico et al., 2015) and benzyl alcohol has been disclosed to be generated from benzaldehyde's reduction by the action of alcohol dehydrogenase (Long \& Ward, 1989).

\subsubsection{Volatile compounds that are evaporated during baking}

2,3-butanedione as well as the alcohols 1-propanol, 2-methyl-1-propanol, 3-methyl-1butanol and 2-methyl-1-butanol showed a decrease in the peak areas in the crumb as a result of a partial evaporation during baking consequence of their low boiling point (behaviour A). While the crumb is below $100{ }^{\circ} \mathrm{C}$, since the water is evaporating with the heat of the oven, the corresponding boiling points are $88^{\circ} \mathrm{C}$ for 2,3 -butanedione, $97^{\circ} \mathrm{C}$ for 1-propanol, $108{ }^{\circ} \mathrm{C}$ for 2-methyl-1-propanol and $130{ }^{\circ} \mathrm{C}$ for 2-methyl-1-butanol and 3-methyl-1-butanol. Surprisingly, ethyl octanoate and furfural were also evaporated during baking. In the case of ethyl octanoate, since its boiling point is $209^{\circ} \mathrm{C}$, a possible explanation for their losses may be associated to its hydrolysis that could be catalysed by the heat (Ramey \& Ough, 1980) at the beginning of the baking step. However, furfural has not been reported as normally lost during baking. Their losses could be attributed to a tiny difference in the solvent extraction efficacy between the dough and the crumb.

\subsubsection{Volatile compounds that increase during baking}


The other 22 volatile compounds presented a visible increase during baking (behaviour B, C, D and F). Acetoin, acetic acid, 2,3-butanediol, phenylethyl alcohol, benzyl alcohol, furfuryl alcohol, 4-vinylguiaicol, butyrolactone, methional and benzaldehyde can be also generated by Maillard reactions (Jensen et al., 2011; Martínez-Anaya, 1996; Poinot et al., 2010; Pico et al., 2015), which take place with the high temperatures applied during baking and lead to the increase of these volatile compounds' concentration. On the other hand, the volatile compounds from lipids oxidation, that is to say nonanal, 2-(E)-nonenal, hexanal, 1-hexanol, hexanoic acid, benzyl alcohol, benzaldehyde, 2,4-decadienal and 1-octen-3-ol, also increased through baking as a result of the cleavage of the hydroperoxides (Guinet \& Godon, 1994) generated by lipoxygenases during the fermentation stage.

For their part, all the isoacids (2-methylpropanoic, 3-methylbutyric acid, 2methylbutyric acid) showed also an increase during baking, which could be also the result of the oxidation of the corresponding Ehrlich amino acids (Birch et al., 2014) at the beginning of the baking, since they are mainly generated through fermentation. Butyric acid also increased during baking, which could be associated to an oxidation of butanal, although butanal was not detected since it should elute during the solvent delay. Similarly, ethyl lactate also increased with the baking step. Although esters are normally generated from fermentation through the fatty acids pathway in the yeast cell (Birch et al., 2014), they can be also generated by the reaction between the acid (lactic acid) and the alcohol (ethyl alcohol) (Frasse et al., 1993). This esterification reaction could take place during baking since the heat could act as a catalyser at the beginning of the baking process.

Finally, phenylacetaldehyde is the only one that stayed constant during baking, which could be the result of an intensive generation by the Ehrlich pathway (Birch, Petersen, 
Arneborg, \& Hansen, 2013) at the beginning of the fermentation and a poor production through Maillard reactions (Martínez-Anaya, 1996).

\subsubsection{Volatile compounds exclusively generated during baking}

2-Pentylfuran was the only volatile compound that was not detected in the dough, but only in the crumb. As explained before, it could be generated by fermenatation, lipid oxidation and Maillard reactions. However, if it was present in the dough by fermentation, it should have been under the limits of detection of the method. Therefore, we can conclude that it is generated in the crumb due to the high temperatures applied during baking, which lead to Maillard reactions increasing the amount of 2-(E)-nonenal as a consequence of the cleavage of the hydroperoxides. In fact, its concentration in crumb has been reported to increase with the temperature (Birch et al., 2013).

\subsection{Implications of this study in the ways of improving the aroma of gluten-free bread}

Maize starch dough fermented for 90 min was characterised by the presence of volatile compounds from fermentation, mainly 2,3-butanedione, acetoin, 2-methyl-1-propanol, 3-methyl-1-butanol, 2-methyl-1-butanol, 1-propanol, phenylethyl alcohol, acetic acid, isobutyric acid, 3/2-methylbutyric acid and ethyl octanoate. All of them have been reported to have a positive impact on the sensory quality of wheat bread (Pico et al., 2015). Acetic acid improves bread aroma when present in small amounts but it has a negative effect in excessive concentration (Ferreira \& dos Reis, 2014). Nevertheless, in moderate concentrations acetic acid could act as suppressor of moulds and ropiness (Ferreira \& dos Reis, 2014). 2,3-butanedione, 2-methyl-1-propanol, 3-methyl-1-butanol, 2-methyl-1-butanol, 1-propanol and ethyl octanoate were partially volatilised during baking and only 2,3-butanedione and 3-methyl-1-butanol have been reported with low

odour thresholds (OT) (Table 2). Acetoin, acetic acid, phenylethyl alcohol, isobutyric acid and 3/2-methylbutyric increased after baking, but only acetoin and 3/2- 
methylbutyric have been reported with a low-medium OTs. Therefore, most of the volatile compounds from fermentation with pleasant notes were evaporated or have been reported with high OTs (Table 2). In consequence, the fermentation process should be encouraged in order to improve the gluten-free bread aroma. The amount of yeast, the fermentation time and temperature, the kind of microorganism or the reduction of salt are some suggestions that should be studied in gluten-free breads for increasing the fermentation activity.

Small amounts of volatile compounds from lipids oxidation were also found in maize starch dough fermented for 90 min, such as hexanal, 1-hexanol, 1-octen-3-ol, nonanal, 2-(E)-nonenal and 2,4-(E,E)-decadienal. Hexanal, 1-octen-3-ol and 2,4-(E,E)-decadienal have been reported to have a negative impact on the sensory quality of wheat bread (Pico et al., 2015). In the case of nonanal and 2-(E)-nonenal, there have been some controversies. On the one hand, they have been described as odorants with pleasant aroma properties (Paraskevopoulou et al., 2012) due to its citrus and cucumber notes, respectively. However, on the other hand, they have also been characterised by fattytallow notes (Table 2). Only 1-hexanol has been classified with high OTs but the rest have been described as very aroma-active compounds in wheat bread crumb with OT significantly low. In order to decrease the generation of volatile compounds from lipid oxidation and improve the gluten-free bread aroma, the amount of oil is suggested to be reduced as far as possible.

Finally, as it has been shown throughout the manuscript, the volatile compounds found in maize starch dough and crumb have been commonly reported in wheat breads in the literature until now. Thus, the main differences are likely to be present in the crust and, therefore, the crucial odorants that improve the aroma of gluten-free bread should be found in the crust. 


\section{Conclusions}

31 volatile compounds, commonly found in the literature of wheat bread, have been detected in the dough and crumb of maize starch-based bread employing a solvent extraction methodology and GC/MS. In the 0 min fermented dough, the most abundant compounds were 2,3-butanedione, 2-methyl-1-propanol, 3/2-methyl-1-butanol, acetic acid, 2,3-butanediol, isobutyric acid and ethyl octanoate. During fermentation there was an increase of 1-propanol, acetoin and phenylethyl alcohol, which after $45 \mathrm{~min}$ of fermentation were also abundant. After baking, all of the above-mentioned volatile compounds were notably present in the crumb, but hexanal, 1-octen-3-ol and nonanal were moderately present too. It was also concluded that an increase in the fermentation activity as well as a reduction of the oil content in the recipe may lead to maize starchbased breads with an improved flavour. Since all volatile compounds found in maize starch doughs and crumbs have been previously reported in wheat bread, results indicate that the crucial odorants resulting in gluten-free breads with stronger aroma may come from their crust.

\section{Acknowledgements}

This study was supported by a grant from the Spanish Ministry of Science and Innovation (Grant: AGL2011-23802). Joana Pico would like to thank the University of Valladolid and for her $\mathrm{PhD}$ contract. The authors would like to thank Daniel Marriott for the revision of the English scientific language. The authors are also grateful to Octavio Rivera for the help offered with breads preparation. 


\section{References}

Aguilar, N., Albanell, E., Miñarro, B., Gallardo, J., \& Capellas, M. (2015). Influence of final baking technologies in partially baked frozen gluten-free bread quality. Journal of Food Science, 80, 619-626.

Berry, D. R., \& Watson, D. C. (1987). Production of organoleptic compounds. In Berry, D. R., Russell, I., Stewart, G. G. (Eds), Yeast Biotechnology (pp. 345-368). London: Allen and Unwin.

Birch, A. N., Petersen, M. A., Arneborg, N., \& Hansen, Å. S. (2013). Influence of commercial baker's yeasts on bread aroma profiles. Food Research International, 52, 160-166.

Birch, A. N., Petersen, M. A., \& Hansen, Å. S. (2013). The aroma profile of wheat bread crumb influenced by yeast concentration and fermentation temperature. $L W T$ - Food Science and Technology, 50, 480-488.

Birch, A. N., Petersen, M. A., \& Hansen, Å. S. (2014). Aroma of Wheat Bread Crumb. Cereal Chemistry, 91 (2), 105-114.

Cho, I. H., \& Peterson, D. G. (2010). Chemistry of bread aroma: A review. Food Science and Biotechnology, 19(3), 575-582.

Coghe, S., Benoot, K., Delvaux, F., Vanderhaegen, B., \& Delvaux, F.R. (2004). Ferulic acid release and 4-vinylguaiacol formation during breewing and fermentation: indications for feruloyl esterase activity in Saccharomyces Cerevisiae. Journal of Agricultural and Food Chemistry, 52 (3), 602-608.

Corral, S., Salvador, A., \& Flores, M. (2015). Elucidation of key aroma compounds in traditional dry fermented sausages using different extraction techniques. Journal of the Science of Food and Agriculture, 95(6), 1350-1361. 
Drapon, R., \& Richard-Molard, D. (1979). Influence de divers procédés technologiques sur la formation de l'ârome du pain. Actes du colloque CNERNA. Paris: Ed. du Centre Nacional de la Reserche Scientifique.

Ehsani, M., Fernandez, M. R., Biosca, J. A., Julien, A., \& Dequin, S. (2009). Engineering of 2,3-Butanediol Dehydrogenase To Reduce Acetoin Formation by Glycerol-Overproducing, Low-Alcohol Saccharomyces cerevisiae. Applied Environmental Microbiology, 75, 3096-3205.

Ferreira, R. P., \& dos Reis, P. M. (2014). Engineering aspects of cereal and cereal based products (1st ed). Florida: CRC Press, (Chapter 7).

Frasse, P., Lambert, S., Richard-Molard, D., \& Chiron, H. (1993). The influence of fermentation on volatile compounds in French bread dough. LWT - Food Science and Technology, 26, 126-132.

Gardner, H. W. (1975). Decomposition of linoleic acid hydroperoxides, Enzymic reactions compared with nonenzymic. Journal of Agricultural and Food Chemistry, 23 (2), 129-136.

Gassenmeier, K., \& Schieberle, P. (1995). Potent aromatic compounds in the crumb of wheat bread (French-type) - influence of pre-ferments and studies on the formation of key odorants during dough processing. Zeitschrift Für LebensmittelUntersuchung Und -Forschung, 201, 241-248. x

Grosch, W., \& Schieberle, P. (1997). Flavor of cereal products - A review. Cereal Chemistry, 74(2), 91-97.

Guillén, M. D., Cabo, N., Ibargoitia, M. L., \& Ruiz, A. (2005). Study of both sunflower oil and its headspace throughout the oxidation process. Occurrence in the headspace of toxic oxygenated aldehydes. Journal of Agricultural and Food Chemistry, 53, 1093-1101. 
Guinet, R., \& Godon, B. (1994). La Panification Française. (1st ed). Paris: Lavoisier.

Klensporf, D., \& Jeleń, H. H. (2008). Effect of heat treatment on the flavor of oat flakes. Journal of Cereal Science, 48(3), 656-661.

Jensen, S., Oestdal, H., Skibsted, L. H., Larsen, E., \& Thybo, A. K. (2011). Chemical changes in wheat pan bread during storage and how it affects the sensory perception of aroma, flavour, and taste. Journal of Cereal Science, 53(2), 259-268.

Long, A., \& Ward, O. P. (1989). Biotransformation of benzaldehyde by Saccharomyces cerevisiae: Characterization of the fermentation and toxicity effects of substrates and products. Biotechnology and bioengineering, 34 (7), 933-941.

Majcher, M., \& Jeleń, H. H. (2009). Comparison of suitability of SPME, SAFE and SDE methods for isolation of flavor compounds from extruded potato snacks. Journal of Food Composition and Analysis, 22(6), 606-612.

Makhoul, S., Romano, A., Capozzi, V., Spano, G., Aprea, E., Capellin, L., Benozzi, E., Scampicchio, M., Märk, T. D., Gasperi, F., El-Nakat, H., Guzzo, J., Biasioli, F. (2015). Volatile Compound Production During the Bread-Making Process: Effect of Flour, Yeast and Their Interaction. Food and Bioprocess Technology, 8, 19251937.

Márczy, J. S., Németh, A. S., Samu, Z., Háger-Veress, Á., \& Szajáni (2002). Production of hexanal from hydrolyzed sunflower oil by lipoxygenase and hydroperoxid lyase enzymes. Biotechnology letters, 24 (20), 1673-1675.

Martínez-Anaya, M. A. (1996). Enzymes and Bread Flavor. American Chemical Society, 44(9), 2469-2479.

Mayuoni-kirshinbaum, L., Tietel, Z., Porat, R., \& Ulrich, D. (2012). Identification of aroma-active compounds in "wonderful” pomegranate fruit using solvent-assisted 
flavour evaporation and headspace solid-phase micro-extraction methods. European Food Research and Technology, 235(2), 277-283.

Nordstrom, K. (1964). Studies on the formation of volatile esters in fermentations with Brewer's Yeast. Svensk Kemist Tidsskrift, 76, 510-543.

Pacyński, M., Wojtasiak, R. Z., \& Mildner-Szkudlarz, S. (2015). Improving the aroma of gluten-free bread. LWT - Food Science and Technology, 63, 706-713.

Paraskevopoulou, A., Chrysanthou, A., \& Koutidou, M. (2012). Characterisation of volatile compounds of lupin protein isolate-enriched wheat flour bread. Food Research International, 48(2), 568-577.

Pico, J., Bernal, J., \& Gómez, M. (2015). Wheat bread aroma compounds in crumb and crust: A review. Food Research International, 75, 200-215.

Pico, J., Gómez, M., Bernal, J., \& Bernal, J. L. (2016). Analytical methods for volatile compounds in wheat bread. Journal of Chromatography A, 1428, 55-71.

Pico, J., Nozal, M. J., Gómez, M., \& Bernal, J. L. (2016). An alternative method based on enzymatic fat hydrolysis to quantify volatile compounds in wheat bread crumb. Food Chemistry, 206, 110-118.

Poinot, P., Arvisenet, G., Grua-Priol, J., Fillonneau, C., Le-Bail, A., \& Prost, C. (2010). Influence of inulin on bread: Kinetics and physico-chemical indicators of the formation of volatile compounds during baking. Food Chemistry, 119(4), 14741484.

Poinot, P., Arvisenet, G., Grua-Priol, J., Fillonneau, C., Mezaize, S., De Lamballerie, M., Le-Bail, A., Prost, C. (2009). Advances in the understanding of the chemical reactions responsible for bread flavour quality. Czech Journal of Food Sciences, 27, 54-57. 
Quílez, J., Ruiz, J. A., \& Romero, M. P. (2006). Relationships between sensory flavor evaluation and volatile and nonvolatile compounds in commercial wheat bread type baguette. Journal of Food Science, 71, 423-427.

Ramey, D. D., \& Ough, C. S. (1980). Volatile ester hydrolysis or formation during storage of model solutions and wines. Journal of Agricultural and Food Chemistry , 28 (5), 928-934.

Robyt, J. F. (2009) Starch: Chemistry and Technology (3rd ed.). Oxford: Academic Press (Chapter 7).

Saerens, S. M. G., Delvaux, F., Verstrepen, K. J., Van Dijck, P., Thevelein, J. M., \& Delvaux F. R. (2008). Parameters Affecting Ethyl Ester Production by Saccharomyces cerevisiae during Fermentation. Applied and Environmental Microbiology, 74 (2), 454-461.

Schieberle, P., \& Grosch, W. (1994). Potent odorants of rye bread crust-differences from the crumb and from wheat bread crust. Zeitschrift Für LebensmittelUntersuchung Und -Forschung, 198, 292-296.

Villa, G. P., Bartroli, R., López, R., Guerra, M., Enrique, M., Peñas, M., Rodríguez, E., Redondo, D., Iglesias, I., \& Díaz, M. (1992). Microbial transformation of furfural to furfuryl alcohol by Saccharomyces Cerevisiae. Engineering in Life Sciences, 12 (6), 509-512.

Zehentbauer, G., \& Grosch, W. (1998). Crust aroma of baguettes II. Dependence of the concentrations of key odorants on yeast level and dough processing. Journal of Cereal Science, 28, 93-96. 
Table 1. Volatile compounds studied in the $0 \mathrm{~min}, 45 \mathrm{~min}$ and $90 \mathrm{~min}$ fermented doughs as well as in the final crumb, in order of elution (Rt, retention time). Target $(T)$ and qualifier $(Q 1, Q 2,+Q)$ ions employed for each compound are given in the table. The origin of the volatile compounds is also indicated.

\begin{tabular}{|c|c|c|c|c|c|c|c|c|}
\hline Volatile Compounds & $\begin{array}{c}\text { Rt } \\
\text { Standard } \\
\text { (min) }\end{array}$ & $\begin{array}{c}\text { Rt } \\
\text { Dough } \\
\text { (min) }\end{array}$ & $\begin{array}{c}\text { Rt } \\
\text { Crumb } \\
\text { (min) }\end{array}$ & $\mathbf{T}$ & Q1 & Q2 & $+Q$ & Origin $^{a}$ \\
\hline 2,3-Butanedione & 8.570 & 8.476 & 7.556 & 43 & 31 & 86 & 15 & $F \& M$ \\
\hline 1-Propanol & 9.094 & 8.760 & 8.216 & 31 & 42 & 59 & 60 & $\mathrm{~F}$ \\
\hline 2-Methyl-1-propanol & 10.036 & 10.135 & 9.400 & 43 & 41 & 74 & 55 & $\mathrm{~F}$ \\
\hline Hexanal & 11.405 & 12.407 & 10.906 & 56 & 44 & 72 & 82 & $\mathrm{~L}$ \\
\hline 3-Methyl-1-butanol & 12.479 & 13.296 & 12.174 & 55 & 70 & 41 & 57 & $\mathrm{~F}$ \\
\hline 2-Methyl-1-butanol & 12.488 & 13.304 & 12.183 & 57 & 41 & 70 & 29 & $\mathrm{~F}$ \\
\hline Acetoin & 13.911 & 14.327 & 13.539 & 45 & 88 & 27 & 15 & $F \& M$ \\
\hline Ethyl lactate & 15.472 & 16.280 & 15.179 & 45 & 75 & 29 & 19 & $\mathrm{~F}$ \\
\hline 2-Pentylfuran & 17.042 & nd & 16.746 & 81 & 53 & 82 & 138 & $F, L \& M$ \\
\hline 1-Hexanol & 18.641 & 18.168 & 16.890 & 56 & 41 & 42 & 55 & $\mathrm{~L}$ \\
\hline Acetic acid & 18.802 & 17.758 & 17.011 & 45 & 60 & 15 & 29 & $F \& M$ \\
\hline Furfural & 20.772 & 21.493 & 20.922 & 96 & 39 & 29 & 67 & $F \& M$ \\
\hline Methional & 22.262 & 23.299 & 22.827 & 48 & 104 & 76 & 61 & $F \& M$ \\
\hline 2,3-butanediol & 22.789 & 22.187 & 21.371 & 45 & 57 & 29 & 75 & $F \& M$ \\
\hline 1-Octen-3-ol & 23.801 & 24.510 & 24.068 & 57 & 72 & 43 & 85 & $\mathrm{~L}$ \\
\hline Nonanal & 22.120 & 23.453 & 22.655 & 57 & 41 & 70 & 98 & $\mathrm{~L}$ \\
\hline Isobutyric acid & 23.002 & 23.414 & 22.642 & 43 & 41 & 73 & 27 & $\mathrm{~F}$ \\
\hline Benzaldehyde & 25.712 & 26.434 & 25.864 & 106 & 105 & 77 & 51 & $F, L \& M$ \\
\hline Ethyl octanoate & 24.890 & 25.382 & 24.280 & 88 & 101 & 127 & 57 & $\mathrm{~F}$ \\
\hline Butyric acid & 25.449 & 25.678 & 25.276 & 60 & 73 & 42 & 27 & $\mathrm{~F}$ \\
\hline Butyrolactone & 25.676 & 26.538 & 25.540 & 42 & 28 & 86 & 56 & $\mathrm{~F} \& \mathrm{M}$ \\
\hline Furfuryl alcohol & 25.809 & 25.809 & 25.401 & 98 & 81 & 69 & 53 & $\mathrm{M}$ \\
\hline 3-Methylbutanoic acid & 26.294 & 26.542 & 26.201 & 60 & 43 & 87 & 39 & $\mathrm{~F}$ \\
\hline 2-Methylbutanoic acid & 26.298 & 26.556 & 26.208 & 57 & 74 & 87 & 41 & $\mathrm{~F}$ \\
\hline 2-(E)-Nonenal & 26.484 & 27.442 & 27.010 & 70 & 55 & 41 & 83 & $\mathrm{~L}$ \\
\hline Phenylacetaldehyde & 26.662 & 27.730 & 26.544 & 91 & 120 & 92 & 65 & $F \& M$ \\
\hline Hexanoic acid & 28.478 & 30.646 & 29.832 & 60 & 73 & 87 & 41 & $\mathrm{~F} \& \mathrm{~L}$ \\
\hline Benzyl alcohol & 28.718 & 29.648 & 29.290 & 79 & 108 & 91 & 51 & $M \& L$ \\
\hline Phenylethyl alcohol & 29.228 & 29.930 & 29.139 & 91 & 122 & 65 & 77 & $F \& M$ \\
\hline 2,4-(E,E)-Decadienal & 29.620 & 29.798 & 29.377 & 81 & 67 & 95 & 152 & $\mathrm{~L}$ \\
\hline 4-Vinylguaiacol & 31.156 & 31.715 & 31.053 & 150 & 135 & 107 & 77 & $\mathrm{M}$ \\
\hline
\end{tabular}

\footnotetext{
a Pico, Bernal \& Gómez (2015). F = fermentation, L = lipids oxidation, $M=$ Maillard
} 
Table 2. Peak area of the target ions $\left(\times 10^{5}\right)$ of the 31 volatile compounds studied in $0 \mathrm{~min}, 45 \mathrm{~min}$ and $90 \mathrm{~min}$ fermented doughs as well as in the final crumb. Standard deviations (SD) are given after $\pm(n=4)$. Different letters in the same row indicate significant differences in the One-way Anova (significant level 95\%). The odour thresholds of each volatile in water as well as their organoleptic characteristics have been also included.

\begin{tabular}{|c|c|c|c|c|c|c|c|c|c|c|c|}
\hline Volatile compounds & $\begin{array}{l}\text { Omin } \\
\text { Dough }\end{array}$ & \pm & $\begin{array}{l}45 \mathrm{~min} \\
\text { Dough }\end{array}$ & \pm & $\begin{array}{l}90 \text { min } \\
\text { Dough }\end{array}$ & \pm & Crumb & \pm & p-Value & $\begin{array}{c}\text { OT } \\
\left(\mu \mathrm{Kg}^{-1}\right)\end{array}$ & $\begin{array}{c}\text { Organoleptic } \\
\text { characteristics }^{\mathrm{d}, \mathrm{e}, \mathrm{f}, \mathrm{g}}\end{array}$ \\
\hline 2,3-Butanedione & $17.371 \mathrm{~b}$ & 0.900 & $16.938 \mathrm{~b}$ & 1.044 & $25.010 \mathrm{c}$ & 1.679 & $10.648 \mathrm{a}$ & 0.275 & 0.0010 & 6.5 & Buttery \\
\hline 1-Propanol & $0.885 a$ & 0.007 & $8.173 \mathrm{~b}$ & 0.868 & $21.676 \mathrm{c}$ & 1.768 & $8.351 \mathrm{~b}$ & 0.159 & 0.0001 & 6600 & Alcohol-like \\
\hline 2-Methyl-1-propanol & $15.050 \mathrm{a}$ & 0.827 & $42.911 \mathrm{~b}$ & 4.791 & $78.297 \mathrm{C}$ & 7.897 & $25.535 \mathrm{a}$ & 0.089 & 0.0006 & 3200 & Wine, malty \\
\hline Hexanal & $0.460 \mathrm{a}$ & 0.043 & $0.555 \mathrm{a}$ & 0.032 & $0.674 \mathrm{a}$ & 0.048 & $6.969 \mathrm{~b}$ & 0.138 & 0.0000 & 4.5 & Green grass \\
\hline 3-Methyl-1-butanol & $13.099 \mathrm{a}$ & 0.836 & $21.995 \mathrm{~b}$ & 1.399 & $47.323 \mathrm{~d}$ & 2.305 & $33.249 \mathrm{c}$ & 0.961 & 0.0001 & 250 & Balsamic, alcohol \\
\hline 2-Methyl-1-butanol & $11.980 \mathrm{a}$ & 0.673 & $17.751 \mathrm{~b}$ & 0.790 & $35.005 \mathrm{c}$ & 1.409 & $16.508 \mathrm{~b}$ & 0.502 & 0.0001 & 7000 & Fusel, alcoholic \\
\hline Acetoin & $3.460 \mathrm{a}$ & 0.229 & $9.277 \mathrm{~b}$ & 0.793 & $23.946 \mathrm{c}$ & 1.651 & $75.660 \mathrm{~d}$ & 0.779 & 0.0000 & 800 & Buttery \\
\hline Ethyl lactate & $0.762 \mathrm{a}$ & 0.049 & $0.704 \mathrm{~b}$ & 0.082 & $0.903 \mathrm{bc}$ & 0.089 & $1.085 \mathrm{c}$ & 0.078 & 0.0249 & 14000 & Fruity, butter \\
\hline 2-Pentylfuran & 0 & ${ }^{\mathrm{a}} \mathrm{nd}$ & 0 & ${ }^{a}$ nd & 0 & ${ }^{a}$ nd & 8.120 & 0.423 & - & 6 & Floral, fruity \\
\hline 1-Hexanol & $0.167 \mathrm{a}$ & 0.009 & $0.169 \mathrm{a}$ & 0.007 & $0.217 \mathrm{~b}$ & 0.011 & $0.511 \mathrm{c}$ & 0.007 & 0.0000 & 2500 & Sweet alcohol \\
\hline Acetic acid & $116.993 \mathrm{a}$ & 7.364 & $206.283 \mathrm{~b}$ & 11.317 & $381.075 \mathrm{c}$ & 30.531 & $516.319 \mathrm{~d}$ & 0.174 & 0.0001 & 32300 & Vinegar-like \\
\hline Furfural & $0.292 \mathrm{~b}$ & 0.012 & $0.275 \mathrm{~b}$ & 0.029 & $0.304 \mathrm{~b}$ & 0.007 & $0.214 \mathrm{a}$ & 0.012 & 0.0204 & 3000 & Woody, caramellic \\
\hline Methional & $0.032 \mathrm{a}$ & 0.003 & $0.076 \mathrm{~b}$ & 0.008 & $0.093 \mathrm{~b}$ & 0.005 & $0.534 \mathrm{c}$ & 0.022 & 0.0000 & 0.04 & Boiled potato \\
\hline 1-Octen-3-ol & $1.119 \mathrm{a}$ & 0.087 & $2.673 \mathrm{~b}$ & 0.167 & $2.254 \mathrm{~b}$ & 0.152 & $11.815 \mathrm{c}$ & 0.621 & 0.0000 & 1 & Fruity, buttery \\
\hline 2,3-Butanediol & $17.399 \mathrm{a}$ & 1.638 & $89.216 \mathrm{~b}$ & 10.422 & $183.904 \mathrm{c}$ & 22.200 & $340.985 \mathrm{~d}$ & 3.254 & 0.0001 & ${ }^{\mathrm{h}} \mathrm{nf}$ & Mushroom \\
\hline Nonanal & $0.785 \mathrm{a}$ & 0.085 & $2.705 \mathrm{~b}$ & 0.290 & $5.942 \mathrm{c}$ & 0.714 & $12.977 \mathrm{~d}$ & 0.036 & 0.0000 & 1 & Waxy, green, fatty \\
\hline Isobutyric acid & $34.391 \mathrm{a}$ & 2.796 & $37.886 a$ & 3.696 & $55.108 \mathrm{~b}$ & 5.886 & $82.911 \mathrm{c}$ & 0.120 & 0.0007 & 8100 & Butter, fat, cheesy \\
\hline Benzaldehyde & $0.047 \mathrm{a}$ & 0.003 & $0.057 \mathrm{a}$ & 0.002 & $0.052 \mathrm{a}$ & 0.002 & $0.467 \mathrm{~b}$ & 0.015 & 0.0000 & 350 & Bitter almond \\
\hline Ethyl octanoate & $82.868 \mathrm{c}$ & 10.129 & $72.063 \mathrm{bc}$ & 6.281 & $60.400 \mathrm{~b}$ & 8.306 & $2.564 \mathrm{a}$ & 0.239 & 0.0013 & 92 & Fruity, floral \\
\hline Butyric acid & $3.631 \mathrm{a}$ & 0.495 & $4.433 \mathrm{a}$ & 0.098 & $6.169 \mathrm{~b}$ & 0.598 & $9.621 \mathrm{c}$ & 0.172 & 0.0004 & 240 & Cheesy \\
\hline Furfuryl alcohol & $0.171 \mathrm{a}$ & 0.020 & $0.172 \mathrm{a}$ & 0.013 & $0.171 \mathrm{a}$ & 0.015 & $0.311 \mathrm{~b}$ & 0.018 & 0.0000 & 5000 & Sweet, caramel \\
\hline Butyrolactone & $0.173 \mathrm{a}$ & 0.013 & $0.389 \mathrm{~b}$ & 0.025 & $0.413 \mathrm{~b}$ & 0.054 & $1.082 \mathrm{c}$ & 0.039 & 0.0001 & 20000 & Burnt, sweet \\
\hline 3-Methylbutanoic acid & $4.773 \mathrm{a}$ & 0.420 & $4.823 \mathrm{a}$ & 0.392 & $6.361 \mathrm{~b}$ & 0.931 & $10.148 \mathrm{c}$ & 0.080 & 0.0017 & 120 & Cheesy, creamy \\
\hline 2-Methylbutanoic acid & $1.763 \mathrm{ab}$ & 0.184 & $1.431 \mathrm{a}$ & 0.104 & $1.903 \mathrm{~b}$ & 0.138 & $3.831 \mathrm{c}$ & 0.062 & 0.0002 & 100 & Cheesy, acidic \\
\hline 2-(E)-Nonenal & $0 \mathrm{a}$ & ${ }^{a}$ nd & $0.335 \mathrm{~b}$ & 0.022 & $1.098 \mathrm{c}$ & 0.069 & $1.342 \mathrm{~d}$ & 0.018 & 0.0000 & 0.08 & Cucumber, tallow \\
\hline Phenylacetaldehyde & $0.547 \mathrm{a}$ & 0.047 & $0.730 \mathrm{~b}$ & 0.039 & $0.722 \mathrm{~b}$ & 0.034 & $0.726 \mathrm{~b}$ & 0.076 & 0.0572 & 4 & Floral, rose \\
\hline Hexanoic acid & $5.499 \mathrm{a}$ & 0.081 & $6.266 \mathrm{a}$ & 0.248 & $5.914 \mathrm{a}$ & 0.481 & $13.036 \mathrm{~b}$ & 0.477 & 0.0001 & 3000 & Cheesy, fruity \\
\hline Benzyl alcohol & $0.462 \mathrm{a}$ & 0.007 & $0.661 \mathrm{a}$ & 0.047 & $0.655 \mathrm{a}$ & 0.056 & $1.897 \mathrm{~b}$ & 0.162 & 0.0003 & 10000 & Fruity, balsamic \\
\hline Phenylethyl alcohol & $3.332 \mathrm{a}$ & 0.451 & $14.925 \mathrm{~b}$ & 1.537 & $24.595 \mathrm{c}$ & 2.617 & $73.127 \mathrm{~d}$ & 2.957 & 0.0000 & 1100 & Rose-like \\
\hline 2,4-(E,E)-Decadienal & $0.092 \mathrm{a}$ & 0.004 & $0.142 \mathrm{a}$ & 0.011 & $0.993 \mathrm{~b}$ & 0.030 & $1.186 \mathrm{c}$ & 0.072 & 0.0000 & 0.07 & Fatty, deep-fried \\
\hline 4-Vinylguaiacol & $0.953 \mathrm{a}$ & 0.086 & $0.826 a$ & 0.073 & $1.351 \mathrm{~b}$ & 0.102 & $7.888 \mathrm{c}$ & 0.040 & 0.0000 & 3 & Clove \\
\hline
\end{tabular}

${ }^{a}$ nd = not detectable

${ }^{\mathrm{b}}$ Birch, Petersen \& Hansen (2014)

c http://www.leffingwell.com/odorthre.htm d https://pubchem.ncbi.nlm.nih.gov/compound/

e http://www.thegoodscentscompany.com

$\mathrm{f}$ http://www.pherobase.com
${ }^{g}$ Birch, Petersen \& Hansen (2013)

$\mathrm{h}$ nf $=$ not found 
Table 3. Evolution of the volatile compounds classified according the significant differences in the One-way Anova. The codes are obtained from the letters assigned in the order $0 \mathrm{~min}, 45 \mathrm{~min}$ and $90 \mathrm{~min}$ fermented doughs and the crumb, underlined when both letters are together (from Table 2 ).

\begin{tabular}{|c|c|c|}
\hline Behaviour from dough to crumb & $\begin{array}{l}\text { Code in One-Way } \\
\text { Anova }\end{array}$ & Volatile compounds \\
\hline Evaporation from dough to crumb (A) & $\begin{array}{c}b b c a \\
a b c b ; a b c a ; a b d c \\
c \underline{b c b a}\end{array}$ & $\begin{array}{l}\text { 2,3-Butanedione, 1-Propanol, 2-Methyl-1-propanol, } \\
\text { 3-Methyl-1-butanol, 2-Methyl-1-butanol, Ethyl } \\
\text { octanoate }\end{array}$ \\
\hline Continuous increase from dough to crumb (B) & $a b c d, a b \underline{b c} c$ & $\begin{array}{l}\text { Ethyl lactate, Acetoin, Acetic acid, 2,3-Butanediol, } \\
\text { Nonanal, 2-(E)-Nonenal, Phenylethyl alcohol }\end{array}$ \\
\hline $\begin{array}{l}\text { Increase from } 0 \text { min to } 45 \mathrm{~min} \text { fermentation and during baking } \\
\begin{array}{ll}\text { (D) } & \end{array}\end{array}$ & $a b b c$ & Methional, 1-Octen-3-ol, Butyrolactone \\
\hline $\begin{array}{l}\text { Increase from } 0 \text { min to } 45 \text { min fermentation and then steady } \\
\begin{array}{ll}\text { (E) } & \end{array}\end{array}$ & $a b b b$ & Phenylacetaldehyde \\
\hline Generated during baking $(G)$ & - & 2-Pentylfuran \\
\hline
\end{tabular}


Loadings plot (zoom)

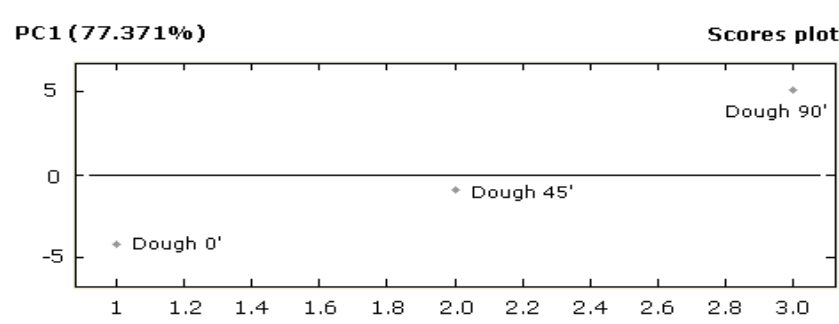

(a)

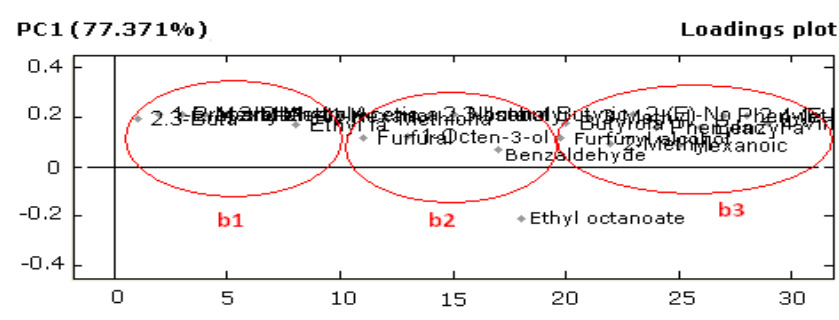

(b)
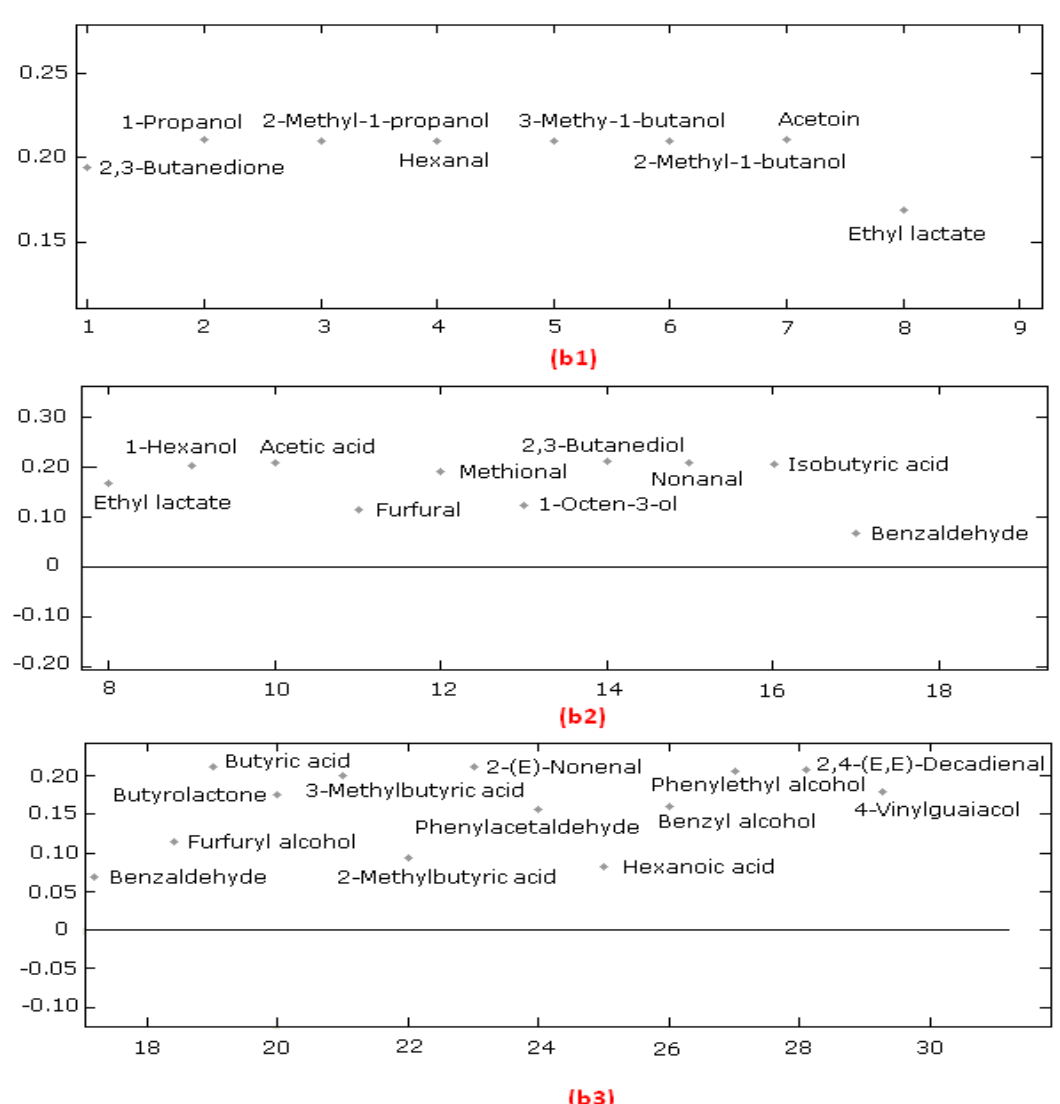

Fig.1. PCA showing the peak areas (target ion) from volatile compounds of the $0 \mathrm{~min}, 45 \mathrm{~min}$ and $90 \mathrm{~min}$ fermented doughs. Scores plot of the dough samples (a), loadings plot of the volatile compounds (b) as well as the expansion of the loadings plot (b1, b2 and b3). 